\title{
Charged System Search Algorithm Utilized for Structural Damage Detection
}

\author{
Zahra Tabrizian, ${ }^{1}$ Gholamreza Ghodrati Amiri, ${ }^{2}$ and Morteza Hossein Ali Beigy ${ }^{1}$ \\ ${ }^{1}$ College of Civil Engineering, Babol Noshirvani University of Technology, Babol, Iran \\ ${ }^{2}$ Centre of Excellence for Fundamental Studies in Structural Engineering, Iran University of Science and Technology, \\ Narmak, Tehran, Iran
}

Correspondence should be addressed to Gholamreza Ghodrati Amiri; ghodrati@iust.ac.ir

Received 12 June 2013; Revised 8 April 2014; Accepted 9 April 2014; Published 20 May 2014

Academic Editor: Gyuhae Park

Copyright (C) 2014 Zahra Tabrizian et al. This is an open access article distributed under the Creative Commons Attribution License, which permits unrestricted use, distribution, and reproduction in any medium, provided the original work is properly cited.

\begin{abstract}
This paper presents damage detection and assessment methodology based on the changes in dynamic parameters of a structural system. The method is applied at an element level using a finite element model. According to continuum damage mechanics, damage is represented by a reduction factor of the element stiffness. A recently developed metaheuristic optimization algorithm known as the charged system search (CSS) is utilized for locating and quantifying the damaged areas of the structure. In order to demonstrate the abilities of this method, three examples are included comprising of a 10-elements cantilever beam, a Bowstring plane truss, and a 39-element three-story three-bay plane frame. The possible damage types in structures by considering several damage scenarios and using incomplete modal data are modeled. Finally, results are obtained from the CSS algorithm by detecting damage in these structures and compared to the results of the PSOPC algorithm. In addition, the effect of noise is shown in the results of the CSS algorithm by suitable diagrams. As is illustrated, this method has acceptable results in the structural detection damage with low computational time.
\end{abstract}

\section{Introduction}

Many civil engineering structures like other structures designed with older codes have been suffering damage and deterioration in recent years, which caused reduction in their performance. Due to this effect, damage assessment of these structures is becoming increasingly essential in order to determine their safety and reliability. The method mentioned in this paper is either visual or nondestructive, which lead us to the best answers. Considering global damage detection methods applicable to complex structures, methods based on modal testing Ewins 1984 [1], and signal processing is made to identify damage in civil engineering and mechanics. These methods study changes in the dynamic characteristics of the structure, such as natural frequencies and mode shapes, which were studied by Doebling et al., 1998, [2] and Hu et al., 2001 [3]. The undamaged and damaged structure compare with the identification of the location and the severity of damage. Natural frequencies and mode shapes are damage indicators which are used as the dynamic parameters.
Methods based on the measurement of natural frequencies are very simple since this parameter can be determined by measuring at only one point of the structure (Salawu, 1997, [4] and Bicanic and Chen, 1997 [5]). Some derivatives of mode shapes, such as mode shape curvatures, are more sensitive to small perturbations than modal displacements and therefore can also be used to detect damage (Pandey et al., 1991 [6]). However, their applicability is minimal since their estimation from experimental data is very difficult, and therefore they are very uncertain from a statistical point of view. Mottershead and Friswell, 1993, have studied model updating methods. In addition to the updating methods based on traditional optimization techniques, new methods have been developed in inverse procedures which are called evolutionary algorithms [7].

In many structures, some local damage may occur during their functional age. In order to develop the efficiency of the structures, it is necessary to properly identify the damage places and their severity and then repair them. There are 
many methods that have been introduced to correctly find out the place and severity of structural damage.

Perera and Torres, 2006, studied a nondestructive global damage detection and assessment methodology based on the changes in frequencies and mode shapes of vibration of a structural system. It was shown that the proposed GA yields a suitable damage places and severity detection from traditional methods [8].

A two-stage method for determining place and severity of multiple structural damage by combining the adaptive neurofuzzy inference system (ANFIS) and particle swarm optimization (PSO) has been proposed by Fallahian and Seyedpoor [9]. In a study, Koh and Dyke [10] have determined the place and severity of multiple damage by iteratively searching for a combination of structural responses that maximizes a correlation coefficient named the multiple damage location assurance criterion (MDLAC) via a genetic algorithm (GA). Damage detection by a hybrid technique including a real-parameter genetic algorithm and grey relation analysis has been presented by He and Hwang [11]. They used first a grey relation analysis to exclude impossible damage places such that the number of design variables could be reduced. Second, a real-parameter genetic algorithm was combined with simulated annealing for finding the actual damage. The damage identification of a beam-like structure has been formulated as an optimization problem, and a GA has been employed to find the damage place and severity by minimizing the cost function which is based on the difference of measured and calculated natural frequencies. A two-stage method for determining the place and severity of multiple structural damage by using an information fusion technique and a GA has been presented by Guo and Li [12]. In the first stage, the damage is localized by using evidence theory, and then a microsearch genetic algorithm (MSGA) has been planned to determine the damage size. Yu and Chen determined the place and severity of damage in a bridge. First, two objective functions are defined. One is defined as minimizing the sum of differences between the modal data before and after damage in traditional way. The other is newly defined based on modal flexibility, which is combined with another function able to predict damage location. Secondly, an improved particle swarm optimization (PSO) algorithm is developed based on the macroeconomic strategies and used to solve the multiple-objective optimization problem on bridge damage identification. The results show that the procedure is very promising for locating and quantifying damaged elements of bridge structures and considerably improves predictions based on the modal flexibility as well as the PSO method [13]. An approach for detecting damage in structural members based on continuum damage model using an algorithm named Big Bang-Big Crunch (BB-BC) has presented suitable accuracy in results [14].

In recent years, the use of metaheuristic methods has increased and great efforts to increase the power of algorithms (Efficiency) and reduce optimization time (more convergence speed) have been done. Recently a new and robust algorithm was presented by Kaveh and Talatahari so called charged system search [15]. This algorithm is based on some laws from electrostatics and the Newtonian mechanics.
The charged system search (CSS) utilizes a number of charged particles (CP) which affect each other based on their fitness values and separation distances considering Coulomb, Gauss, and Newtonian laws. The resultant forces and the motion laws determine the new location of the particles. The harmony search-based handling approach is utilized for controlling the variable constraint.

In this paper, the CSS algorithm is utilized to predict the damage place and severity for different types of structures. The structure is modeled with the finite element method and the damage identification is performed at element level with incomplete modal data.

In order to show the power of the CSS algorithm in structural damage detection, the obtained results are compared to the results of the PSOPC algorithm [16]. PSOPC algorithm is a particle swarm optimization method with passive congregation's capacity [17]. High abilities of this algorithm with acceptable results in structural damage detection are illustrated [16].

The results show that the proposed method is capable of detecting the location and severity of diagnosis; even in large-scale structures with a large number of damaged elements it achieved acceptable results. The effect of the noise is considered by assigning the noise in natural frequencies on the results of the CSS algorithm. The graphs indicate that the noise in input data may reduce the accuracy of damage detection.

\section{Theory}

Existing Structural damage detection techniques can be classified into two major categories: the dynamic and static methods [18]. Both methods are based on the finite element utilizing experimental test data requiring dynamic and static test data, correspondingly. In addition, dynamic methods have shown their advantages in comparison with static ones. The natural frequencies of a structure can be considered to be valuable with the dynamic data. Determining the level of correlation between the calculated and predicted natural frequencies can provide a simple tool for finding the place and severity of structural damage [19]. Structural damage detection is calculated with changes in structural characteristics and it is possible with global evaluating. Doebling et al. have discussed vibration-based techniques in a literature review [20]. In this section the construction of dynamics of damaged structures is discussed.

The parameter vector used for evaluating the correlation coefficients (the ratio of the changes first $n_{f}$ natural frequency, $\Delta F$, due to structural damage) is

$$
\Delta F=\frac{F_{N}-F_{E}}{F_{N}},
$$

where $F_{N}$ and $F_{E}$ denote the natural frequency vectors of the undamaged and damaged structure. Similarly, the parameter vector predicted from an analytical model can be defined correspondingly as

$$
\delta F(X)=\frac{F_{N}-F(X)}{F_{N}},
$$


where $F(X)$ is a natural frequency vector that can be predicted from an analytic model and $X=\left[x^{1}, x^{2}, \ldots, x^{n}\right]$ represents a damage variable vector containing the damage severity of all $n$ structural elements. Given a pair of parameter vectors, one can estimate the level of correlation in several ways. An efficient way is to evaluate a correlationbased index, termed the multiples damage location assurance criterion (MDLAC) and covered in the following form [19]:

$$
\begin{array}{r}
\operatorname{MDLAC}(X)=\frac{\left|\Delta F^{T} \cdot \delta F(X)\right|^{2}}{\left(\Delta F^{T} \cdot \Delta F\right)\left(\delta F^{T}(X) \cdot \delta F(X)\right)}, \\
0<\operatorname{MDLAC}<1 .
\end{array}
$$

Two frequency change vectors are compared with MDLAC: one calculated from the structural tests and the other from a structural model analysis. When the vector of analytical frequencies becomes the same as the frequency vector of the damaged structure, MDLAC will be maximal. That is, $F(X)=F$, so considering this theory can be used to find a set of damage variables maximizing the MDLAC using an optimization algorithm,

$$
\begin{array}{ll}
\text { Find } & X=\left[x_{i}, x_{2}, \ldots, x_{n}\right] \\
\text { Maximize: } & w(X)=\operatorname{MDLAC}(X) .
\end{array}
$$

The damage severity can take values only from the set that is given from [ $\left.\begin{array}{ll}0 & 1\end{array}\right]$, a set of continuous values. Moreover, the objective function that should be maximized is $w$. As mentioned, the damage occurrence in a structural element decreases the element stiffness. Thus, one of the methods for the damage identification problem is simulation damage by decreasing one of the stiffness parameters of the element such as the modulus of elasticity $(E)$, cross-sectional area $(A)$, and inertia moment $(I)$. In this study, the damage variables are defined via a relative reduction of the elasticity modulus of an element as

$$
K_{i}^{d}=\left(1-x_{i}\right) K_{i}^{h} .
$$

$K_{i}^{d}$ is the stiffness matrix of damaged element $i$ and $K_{i}^{h}$ is the stiffness matrix of healthy element $i$.

$E$ is the primary modulus of elasticity and $E_{i}$ is the final modulus of elasticity of the $i$ th element. The MDLAC as an objective function for the optimization algorithm is more sensitive to damaged elements than undamaged elements. It means that this method can find the true place of the damaged elements but it may find an undamaged element as a damaged one. Therefore, in this study, a new function and new optimization algorithm is discussed; the new function is presented as [21]

$$
\operatorname{obj}(X)=\frac{1}{n_{f}} \sum_{i=1}^{n_{f}} \frac{\min \left(f_{x i}, f_{E i}\right)}{\max \left(f_{x i}, f_{E i}\right)},
$$

where $f_{x i}, f_{E i}$ are the $i$ th components of vectors $F(X)$ and $F_{E}$, correspondingly.

The obj $(X)$ function can rapidly find the locations of healthy elements when compared to the MDLAC; however, it is very probable that it finds a damaged element as a healthy one. Therefore, in this study, a combinational function of (3) and (6), called here the efficient correlation-based index (ECBI), is used as [21]

$$
\operatorname{ECBI}(X)=\frac{1}{2}(\operatorname{MDLAC}(X)+\operatorname{obj}(X)) .
$$

\section{Charged System Search Algorithm}

A new type of metaheuristic algorithms is introduced by Kaveh and Talatahari [15] which is called charge system search. The charged system search (CSS) is based on Coulomb and Gauss laws from electrical physics and the governing laws of motion from the Newtonian mechanics. In this algorithm, each agent is a charged particle (CP). Each $\mathrm{CP}$ is considered as a charged sphere which exerts an electric force on other CPs according to Coulomb and Gauss laws. The resultant forces and the motion laws determine the new location of the CPs [22]. The new positions of the charged particles in the first iteration are determined randomly and for next iterations are obtained as follows:

$$
\begin{aligned}
X_{j, \text { new }}= & \operatorname{rand}_{j, 1} \cdot k_{a} \cdot \frac{F_{j}}{m_{j}} \cdot \Delta t^{2} \\
& +\operatorname{rand}_{j 2} \cdot k_{v} \cdot V_{j, \text { old }} \cdot \Delta t+X_{j, \text { old }} \\
& V_{j, \text { new }}=\frac{X_{j, \text { new }}-X_{j, \text { old }}}{\Delta t},
\end{aligned}
$$

where $K_{a}$ and $K_{v}$ are the acceleration and the velocity coefficients, respectively, rand $d_{j, 1}$ and rand ${ }_{j, 2}$ are two random uniformly distributed in the range $(0,1)$, and the resultant forces vector for $j$ th $\mathrm{CP}, F_{j}$, is calculated as

$$
\begin{array}{r}
F_{j}=q_{i} \sum_{i, i \neq j}\left(\frac{q_{i}}{a^{3}} r_{i j} \cdot i_{1}+\frac{q_{i}}{r_{i j}^{2}} \cdot i_{2}\right) p_{i j}\left(X_{i}-X_{j}\right) \\
j=1,2, \ldots, N \\
i_{1}=1, i_{2}=0 \Longleftrightarrow r_{i j}<a, \\
i_{1}=0, i_{2}=1 \Longleftrightarrow r_{i j} \geq a,
\end{array}
$$

where the magnitude of charge for each CP, $q_{i}$, is defined as

$$
q_{i}=\frac{\text { fit }(i)-\text { fitworst }}{\text { fitbest }- \text { fitworst }}, \quad i=1,2, \ldots, N,
$$

where fitbest and fitworst are the best and the worst fitness of all the CPs, fit $(i)$ is the fitness of the agent $i$, and $N$ is the total number of charged particles. The separation distance between two CPs, $r_{i j}$, is obtained as follows:

$$
r_{i j}=\frac{\left\|X_{i}-X_{j}\right\|}{\left\|\left(X_{i}+X_{j}\right) / 2-X_{\text {best }}\right\|+\varepsilon},
$$

where $X_{i}$ and $X_{j}$ are the positions of the $i$ th and $j$ th CPs, $X_{\text {best }}$ is the position of the best current $\mathrm{CP}$, and $\varepsilon$ is a small positive 


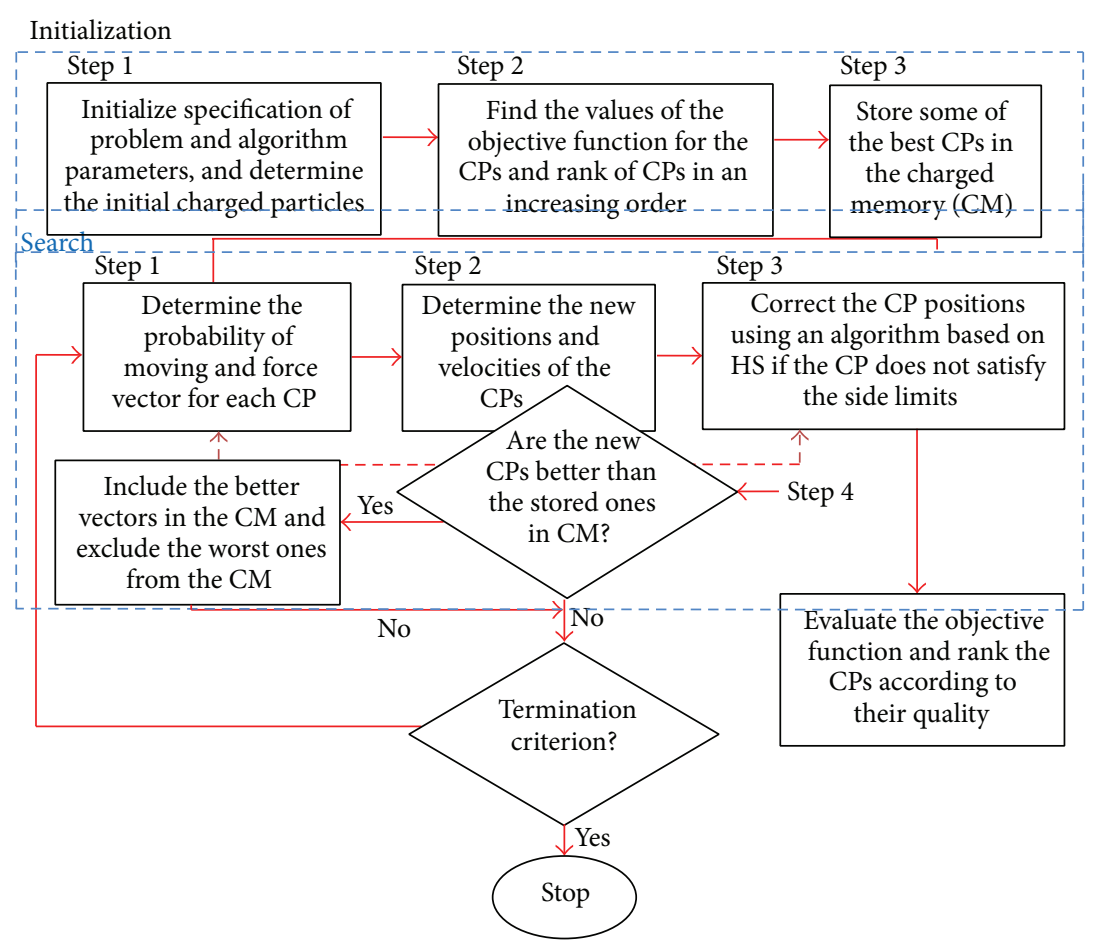

FIGURE 1: Flowchart of the CSS algorithm.

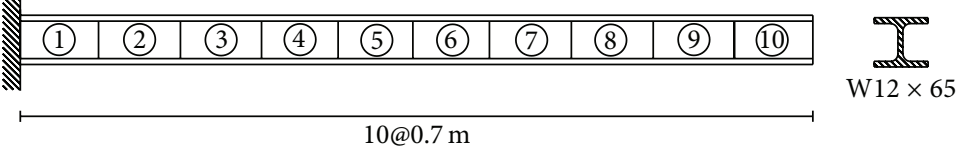

FIGURe 2: A cantilever beam geometry.

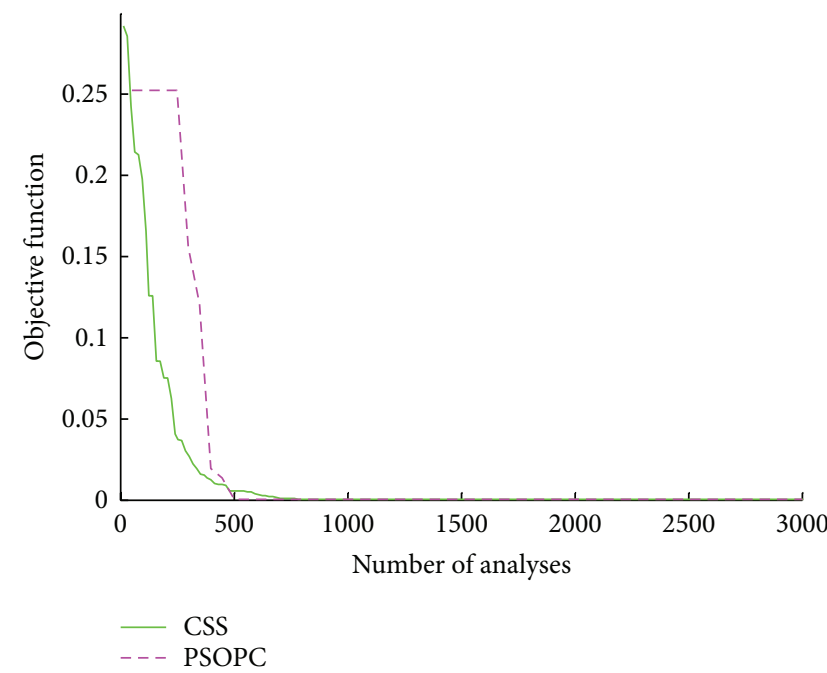

(a) Scenario 1

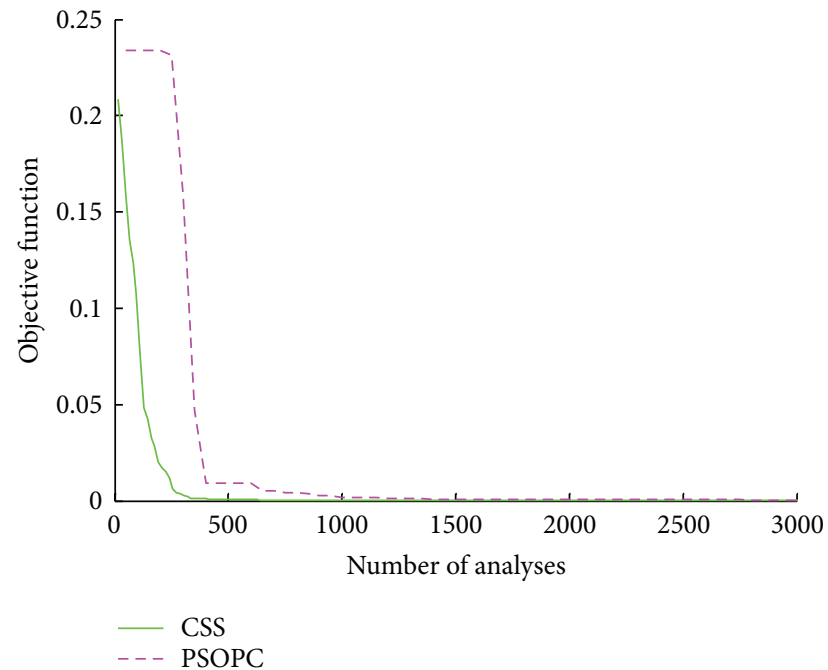

(b) Scenario 2

FIGURE 3: The convergence history of the 10-element beam for the CSS and PSOPC algorithms. 


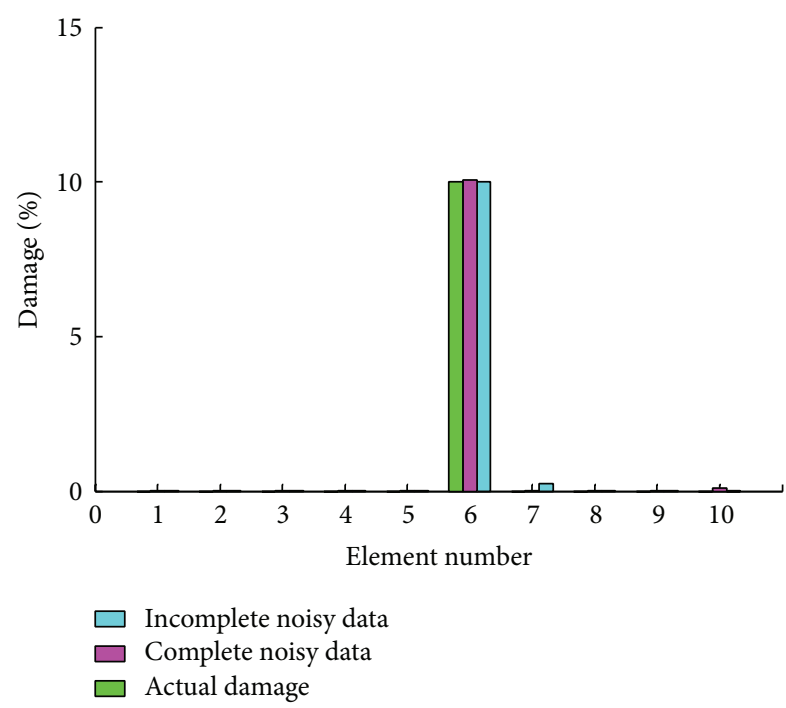

FIGURE 4: Damage distribution of cantilever beam using the complete and incomplete noisy data in Scenario 1.

number. The probability of moving each $\mathrm{CP}$ toward the other $\mathrm{CPs}$ is determined using the following function:

$$
p_{i j}= \begin{cases}1, & \frac{\text { fit }(i)-\text { fitbest }}{\text { fit }(j)-\text { fit }(i)}>\text { rand } \vee \text { fit }(j)>\text { fit }(i), \\ 0, & \text { otherwise. }\end{cases}
$$

After production of the new position of the CPs, if any component of the solution vector swerves off the allowable bounds, correct its position using the harmony search-based handling approach as described in [23].

The charged memory (CM) is used to save a number of the best solutions up to the iteration. The better new solutions are included in the $\mathrm{CM}$ and the worst ones are excluded from the CM. The flowchart of the CSS algorithm is illustrated in Figure 1.

\section{Objective Function}

The CSS algorithm attempts to minimize an objective assessment function for the best solution to a given problem. This function is used to provide a measure of how individuals have performed in the problem domain. In the case of a minimization problem, the fittest individuals will have the lowest numerical value of the associated objective function. In this study, the statement for the objective function is given as

$$
F=f(d),
$$

where $d=\left\{d_{1}, d_{2}, \ldots, d_{N}\right\}$ are damage parameters at the $N$ elements.

To create the objective function, $F$, it is essential to use some kind of output variables of the structure that are sufficiently sensitive to the damage parameter being identified in order to avoid ill conditioning problems. The mode shapes and the natural frequencies can be obtained by

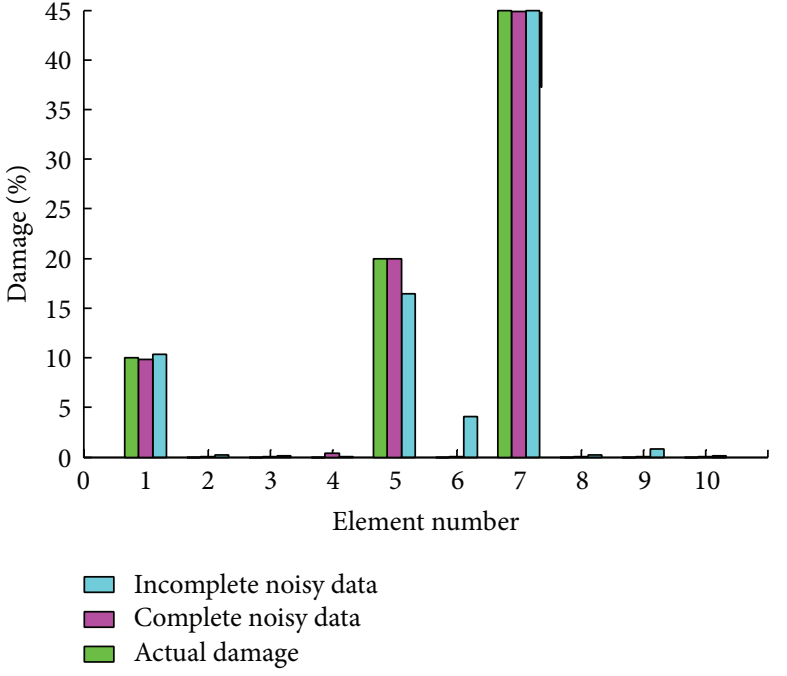

FIGURE 5: Damage distribution of cantilever beam using the complete and incomplete noisy data in Scenario 2.

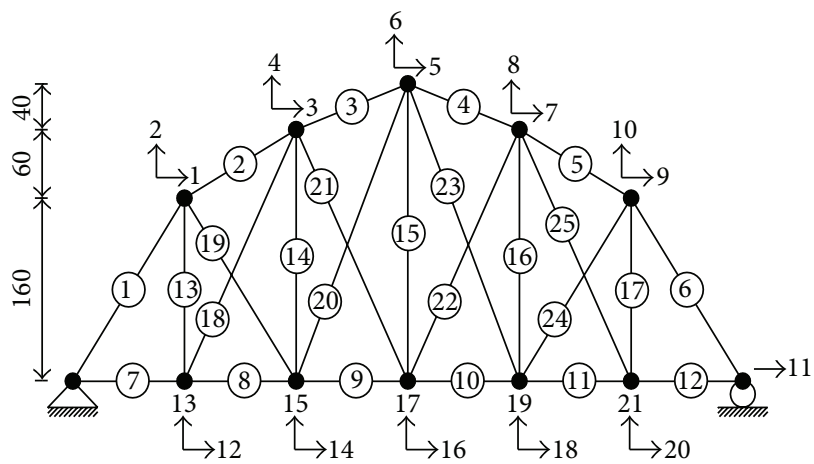

FIgURE 6: A 25-bar Bowstring truss.

modal analysis methods. Natural frequencies are relatively easy to measure and have been used by many researchers.

To identify localized damage, because of the greater experience variations in the locality of the affected area, mode shapes offer a better option (Salane and Baldwin, 1990 [24]; Salawu and Williams, 1995 [25]; Ndambi et al., 2002 [26]). It is necessary to note that the success of this process depends on the quality and place selection (for test) of the measurements which are able to reflect the damage.

Because of this, assuming that only a few natural frequencies and mode shapes of the lower modes are available, frequency objective functions from incomplete data are considered in this paper to detect damage.

\section{Numerical Simulation Study}

In this section, two examples consisting of a ten-element cantilever beam, a Bowstring plane truss, and a three-story threebay unbraced frame structures are presented to examine the charged system search algorithm. The final results are then compared to the solutions of particle swarm optimization 


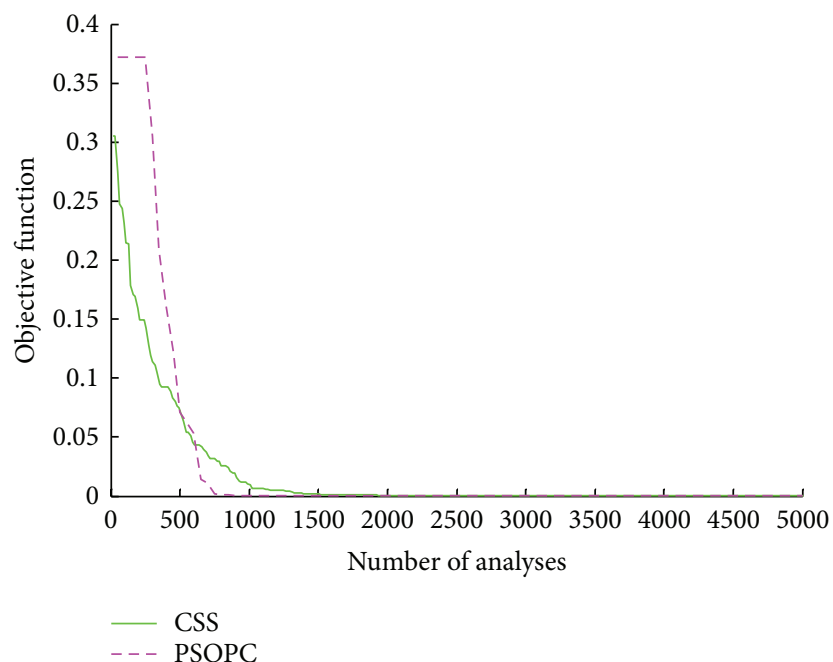

(a) Scenario 1

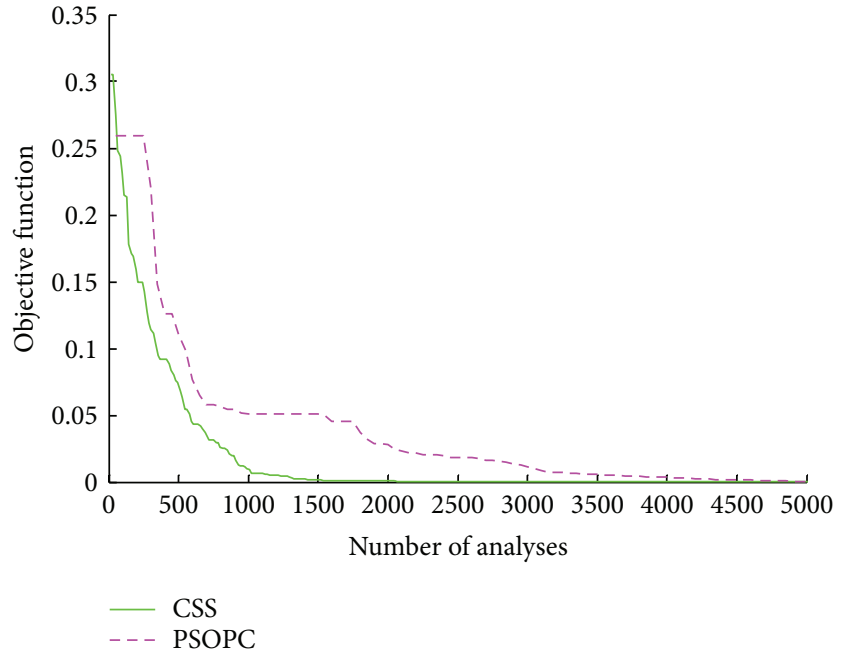

(b) Scenario 2

FIGURE 7: The convergence history of the Bowstring truss for the CSS and PSOPC algorithms.

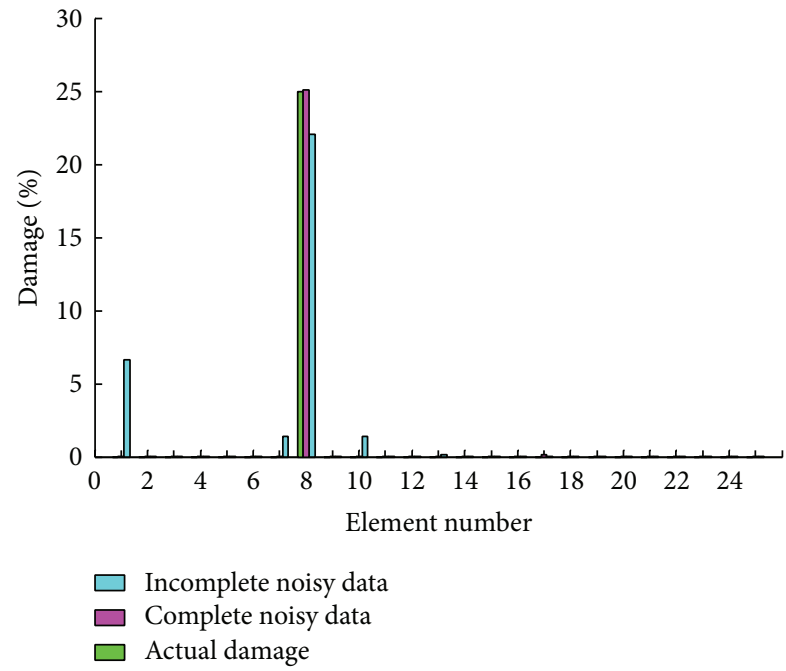

FIGURE 8: Damage distribution of Bowstring truss using the complete and incomplete noisy data in Scenario 1.

with passive congregation algorithm to demonstrate the performance of this work.

In CSS algorithm, the effect of the pervious velocity and the resultant force affecting a CP can decrease or increase based on the values of the $k_{v}$ and $k_{a}$ defined as [22]

$$
\begin{aligned}
& k_{v}=c\left(1-\frac{\text { iter }}{\text { iter }_{\max }}\right), \\
& k_{a}=c\left(1+\frac{\text { iter }}{\text { iter }_{\max }}\right),
\end{aligned}
$$

where iter is the iteration number, iter $_{\max }$ is the maximum number of the iterations, and $c$ is set to 1 .

For the CSS algorithm, a population of 16 CPs and for PSOPC algorithm a population of 50 particles are used for all

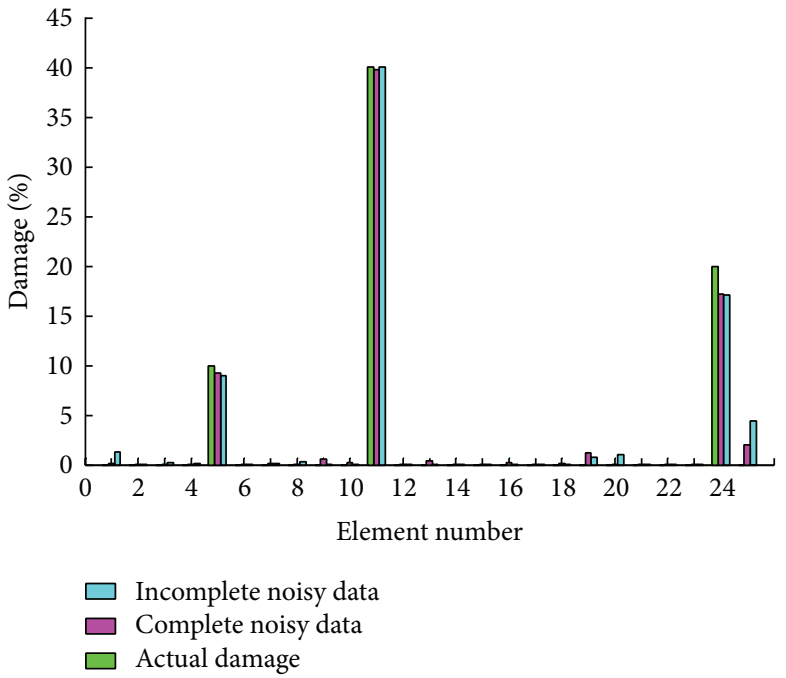

FIgURE 9: Damage distribution of Bowstring truss using the complete and incomplete noisy data in Scenario 2.

TABLE 1: Simulated damage scenarios in cantilever beam.

\begin{tabular}{lcc}
\hline Element number & Scenario 1 & Scenario 2 \\
\hline 1 & & $10 \%$ \\
3 & & \\
5 & $10 \%$ & $20 \%$ \\
6 & & $35 \%$ \\
7 & & \\
9 & & \\
\hline
\end{tabular}

the examples; the stop criterion is considered as maximum number of 3000 and 5000 analyses in first and two other examples, respectively. 


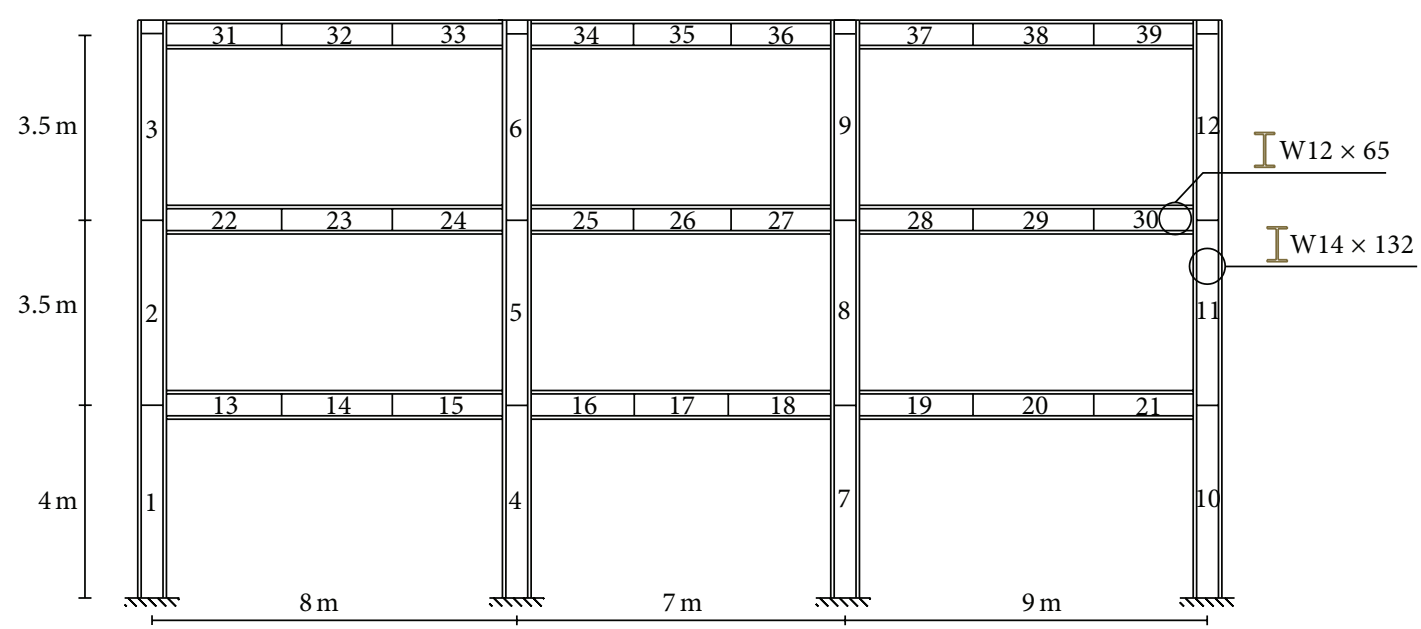

FIGURE 10: Geometry of unbraced plane frame.

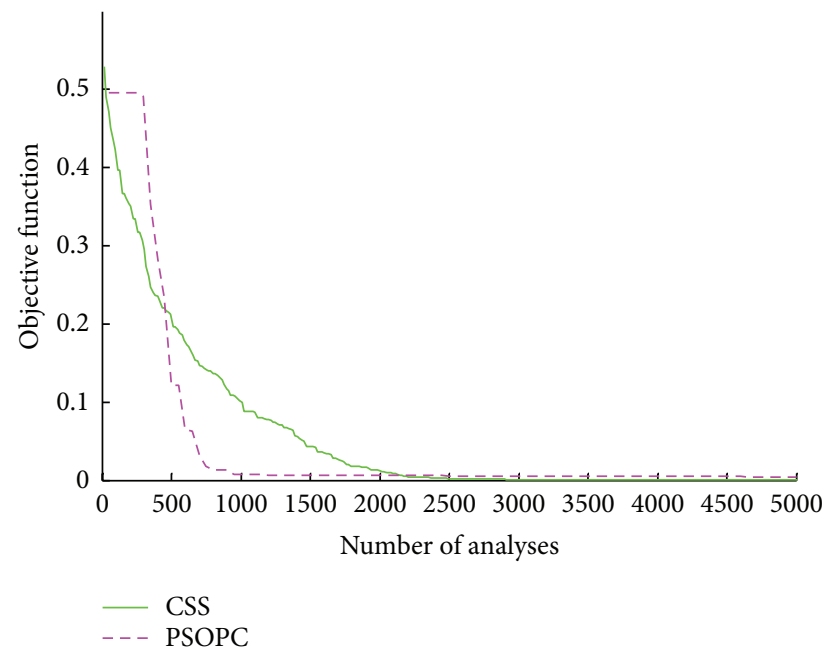

(a) Scenario 1

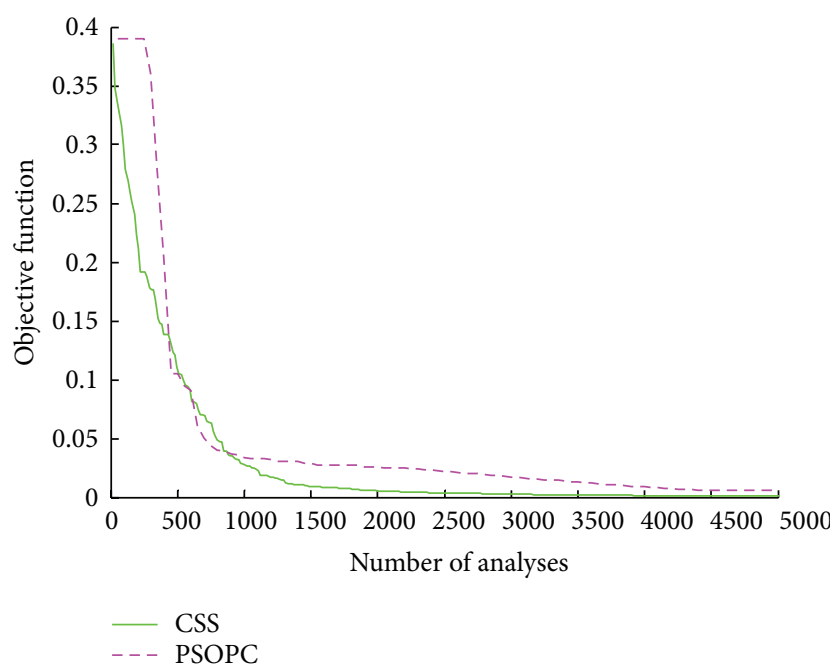

(b) Scenario 2

FIGURE 11: The convergence history of the 39-element frame for the CSS and PSOPC algorithms.

The algorithm has been implemented in the commercial MATLAB software and because of the stochastic nature of the algorithms, each example is independently solved ten times. and 1 .

Damage values have been limited to a region between 0

Example 1. A cantilever steel beam is shown in Figure 2. For the reason of modal analyzing the beam was divided into 10 two-dimensional beam elements with 20 degrees of freedom.

The section of the beam is W12 $\times 65$ with mechanical properties of

$$
\begin{aligned}
& A=0.0123 \mathrm{~m}^{2}\left(19.1 \mathrm{in}^{2}\right), \\
& I=2.218 \times 10^{-4} \mathrm{~m}^{4}\left(533 \mathrm{in}^{4}\right), \\
& E=207 \times 10^{9} \mathrm{~N} / \mathrm{m}^{2}, \\
& \rho=7860 \mathrm{~kg} / \mathrm{m}^{3} .
\end{aligned}
$$

The measured modal responses of the beam before and after damage were created using the proposed forward solver (for each scenario). Instead of experimental measurements, numerically generated measurements were used to estimate the proposed inverse procedure. In this example, the first ten natural frequencies are used for damage detection. Two different simulated damage scenarios are considered (Table 1).

These damage scenarios are considered to represent the effect of severity of damage (stiffness reduction), number of damaged elements, and contribution of damage elements on the results. The results of damage detecting of CSS and PSOPC algorithms are given in Table 2. In order to evaluate the performance of the methods used, the summation of estimated error of damage detection was calculated (Table 2) that is presented as follows:

$$
\text { Error }=\sum\left(d_{A}^{i}-d_{S}^{i}\right)
$$


TABLE 2: Results of damage detection of the 10-element beam using CSS and PSOPC algorithms.

\begin{tabular}{|c|c|c|c|c|c|c|}
\hline \multirow{2}{*}{$\begin{array}{l}\text { Element } \\
\text { number }\end{array}$} & \multicolumn{3}{|c|}{ Scenario 1} & \multicolumn{3}{|c|}{ Scenario 2} \\
\hline & CSS & Actual damage & PSOPC & CSS & Actual damage & PSOPC \\
\hline 1 & 0.000 & 0 & 0.000 & 0.101 & 0.1 & 0.105 \\
\hline 2 & 0.000 & 0 & 0.000 & 0.003 & 0 & 0.000 \\
\hline 3 & 0.000 & 0 & 0.000 & 0.001 & 0 & 0.000 \\
\hline 4 & 0.000 & 0 & 0.000 & 0.000 & 0 & 0.000 \\
\hline 5 & 0.000 & 0 & 0.000 & 0.185 & 0.2 & 0.169 \\
\hline 6 & 0.100 & 0.1 & 0.100 & 0.016 & 0 & 0.037 \\
\hline 7 & 0.000 & 0 & 0.000 & 0.349 & 0.35 & 0.348 \\
\hline 8 & 0.000 & 0 & 0.000 & 0.002 & 0 & 0.000 \\
\hline 9 & 0.000 & 0 & 0.000 & 0.001 & 0 & 0.000 \\
\hline 10 & 0.000 & 0 & 0.000 & 0.000 & 0 & 0.000 \\
\hline Error & 0.0002 & & 0.0000 & 0.0385 & & 0.0752 \\
\hline
\end{tabular}

TABLE 3: The values of objective function of the 10-element beam for algorithms.

\begin{tabular}{|c|c|c|c|c|c|c|c|c|c|c|c|}
\hline \multicolumn{12}{|c|}{ Run number } \\
\hline & 1 & 2 & 3 & 4 & 5 & 6 & 7 & 8 & 9 & 10 & Success \\
\hline \multicolumn{12}{|l|}{ Scenario 1} \\
\hline CSS & $3.4 \times 10^{-06}$ & $5.2 \times 10^{-06}$ & $2.8 \times 10^{-06}$ & $2.7 \times 10^{-06}$ & $8.3 \times 10^{-06}$ & $6.5 \times 10^{-06}$ & $4.1 \times 10^{-06}$ & $3.8 \times 10^{-06}$ & $1.9 \times 10^{-06}$ & $4.4 \times 10^{-06}$ & $100 \%$ \\
\hline PSOPC & $2.5 \times 10^{-07}$ & $1.3 \times 10^{-07}$ & $9.9 \times 10^{-08}$ & $1.4 \times 10^{-07}$ & $2.1 \times 10^{-07}$ & $4.6 \times 10^{-07}$ & $2.6 \times 10^{-07}$ & $1.6 \times 10^{-06}$ & $8.8 \times 10^{-08}$ & $1.1 \times 10^{-07}$ & $100 \%$ \\
\hline \multicolumn{12}{|l|}{ Scenario 2} \\
\hline CSS & 0.0008 & 0.0001 & 0.0009 & 0.0004 & 0.0006 & 0.0002 & 0.0005 & 0.0008 & 0.0009 & 0.0006 & $80 \%$ \\
\hline PSOPC & 0.0003 & 0.0013 & 0.0056 & 0.0004 & 0.0074 & 0.0074 & 0.0080 & 0.0011 & 0.0006 & 0.0085 & $40 \%$ \\
\hline
\end{tabular}

TABLE 4: Cross-sectional areas of truss elements.

\begin{tabular}{lc}
\hline Member & Area $\left(\mathrm{cm}^{2}\right)$ \\
\hline $1-6$ & 18 \\
$7-12$ & 15 \\
$13-17$ & 10 \\
$18-25$ & 12 \\
\hline
\end{tabular}

TABLE 5: Simulated damage scenarios in Bowstring truss.

\begin{tabular}{lcc}
\hline Element number & Scenario 1 & Scenario 2 \\
\hline 3 & & \\
5 & $25 \%$ & $10 \%$ \\
8 & & \\
10 & & $40 \%$ \\
11 & & $20 \%$ \\
24 & \\
\hline
\end{tabular}

where $d_{A}^{i}$ and $d_{S}^{i}$ are the actual and estimated damage of the $i$ th element using the presented method, respectively.

In Table 3, the values of the objective function for CSS and PSOPC algorithms in independent 10 runs are given; the convergence history for the 10 -element beam in scenarios 1 and 2 is shown in Figure 3.
It is seen in Table 2 that in the first scenario where the number of damaged elements is low, the damage identification is well by both algorithms; in the second scenario, the algorithm PSOPC has some wrong in damage detection, so that there is difference between the obtained damage via this algorithm and the actual intensity of damage in the fifth element, and the undamaged sixth element, mistakenly, has been detected to be damaged. Meanwhile, the location and amount of damage in structure are obtained by the CSS algorithm with acceptable accuracy. In order to investigate the noise effects on the results of the CSS method, $0.15 \%$ noise in measurement is considered for the natural frequencies.

Diagrams of the CSS algorithm's damage detection with complete and incomplete dynamic noisy data are plotted in Figures 4 and 5.

As the results show, this method is able to detect the location and magnitude of damaged elements in all scenarios using complete and incomplete noisy data.

Example 2. A Bowstring plane truss with 25 elements is shown in Figure 6. The properties of members of this structure are $E=207 \times 0^{9} \mathrm{~N} / \mathrm{m}^{2}$ and $\rho=7860 \mathrm{~kg} / \mathrm{m}^{3}$ and crosssectional areas of elements are given in Table 4 .

Three scenarios for this truss are considered according to Table 5. 
TABLE 6: Results of damage detection of the 25-bar Bowstring truss using CSS and PSOPC algorithms.

\begin{tabular}{|c|c|c|c|c|c|c|}
\hline \multirow{2}{*}{ Element number } & \multicolumn{3}{|c|}{ Scenario 1} & \multicolumn{3}{|c|}{ Scenario 2} \\
\hline & CSS & Actual damage & PSOPC & CSS & Actual damage & PSOPC \\
\hline 1 & 0.009 & 0 & 0.000 & 0.000 & 0 & 0.000 \\
\hline 2 & 0.000 & 0 & 0.000 & 0.000 & 0 & 0.000 \\
\hline 3 & 0.000 & 0 & 0.000 & 0.000 & 0 & 0.000 \\
\hline 4 & 0.000 & 0 & 0.000 & 0.000 & 0 & 0.000 \\
\hline 5 & 0.000 & 0 & 0.000 & 0.098 & 0.1 & 0.095 \\
\hline 6 & 0.000 & 0 & 0.000 & 0.000 & 0 & 0.000 \\
\hline 7 & 0.000 & 0 & 0.000 & 0.000 & 0 & 0.000 \\
\hline 8 & 0.246 & 0.25 & 0.250 & 0.000 & 0 & 0.000 \\
\hline 9 & 0.001 & 0 & 0.000 & 0.000 & 0 & 0.000 \\
\hline 10 & 0.000 & 0 & 0.000 & 0.000 & 0 & 0.000 \\
\hline 11 & 0.000 & 0 & 0.000 & 0.402 & 0.4 & 0.426 \\
\hline 12 & 0.000 & 0 & 0.000 & 0.000 & 0 & 0.000 \\
\hline 13 & 0.000 & 0 & 0.000 & 0.000 & 0 & 0.000 \\
\hline 14 & 0.001 & 0 & 0.000 & 0.000 & 0 & 0.000 \\
\hline 15 & 0.000 & 0 & 0.000 & 0.000 & 0 & 0.000 \\
\hline 16 & 0.000 & 0 & 0.000 & 0.000 & 0 & 0.000 \\
\hline 17 & 0.000 & 0 & 0.000 & 0.000 & 0 & 0.000 \\
\hline 18 & 0.000 & 0 & 0.000 & 0.005 & 0 & 0.000 \\
\hline 19 & 0.000 & 0 & 0.000 & 0.004 & 0 & 0.075 \\
\hline 20 & 0.000 & 0 & 0.000 & 0.001 & 0 & 0.000 \\
\hline 21 & 0.000 & 0 & 0.000 & 0.000 & 0 & 0.000 \\
\hline 22 & 0.000 & 0 & 0.000 & 0.000 & 0 & 0.000 \\
\hline 23 & 0.000 & 0 & 0.000 & 0.000 & 0 & 0.000 \\
\hline 24 & 0.000 & 0 & 0.000 & 0.185 & 0.2 & 0.000 \\
\hline 25 & 0.000 & 0 & 0.000 & 0.014 & 0 & 0.265 \\
\hline Error & 0.0085 & & 0.0000 & 0.0119 & & 0.1609 \\
\hline
\end{tabular}

In Table 6 the results of two algorithms in all scenarios are compared. Only the first ten natural frequencies are used for damage detection.

The comparison of the objective function for CSS and PSOPC algorithms is made in Table 7, and the convergence history for the Bowstring truss in scenarios 1 and 2 is shown in Figure 7.

In Figures 8 and 9 the results of CSS algorithm in damage detection of this truss that is affected by noise are shown.

Table 7 and Figures 7, 8, and 9 show better results in damage detection by CSS algorithm rather than PSOPC algorithm and also by applying noise in structures.

Example 3. A three-story three-bay frame as shown in Figure 10 is used to verify the damage detection method explained in this paper. The number of elements and nodes is 39 and 34 , respectively.

For unbraced plane frame problem, all columns are $\mathrm{W} 14 \times 132\left(A=0.025 \mathrm{~m}^{2}\left(38.8 \mathrm{in}^{2}\right)\right.$ and $I=6.386 \times$ $\left.10^{-4} \mathrm{~m}^{4}\left(1530 \mathrm{in}^{4}\right)\right)$ and all beams are $\mathrm{W} 12 \times 65$. Young's modulus is $E=207 \mathrm{GPa}(30,000 \mathrm{ksi})$, Poisson's ratio is $v=$ 0.3 , and the mass density is $\rho=7780 \mathrm{~kg} / \mathrm{m}^{3}(0.000728 \mathrm{lb}-$ $\left.\mathrm{s}^{2} / \mathrm{in}^{4}\right)$.
In this example, two scenarios from the aspect of element number and its level of damage were assumed that are given in Table 8. Between ninety natural frequencies, only the first twenty natural frequencies are utilized for damage detection in the first scenario.

The severity of damage detection by PSOPC and CSS algorithms in different members of the frame and in each scenario is shown separately in Table 9. In Table 10, the obtained objective function for both algorithms in each run is given; also the convergence history is shown in Figure 11.

Also, the results of the CSS algorithm damage detection with noisy data are plotted in the diagrams of Figures 12 and 13.

The results of damage detection with two algorithms in this large frame show that in case of only one member damaged, there is more accuracy with PSOPC algorithm in identifying of desired member and obtaining the amount of damage than the CSS algorithm. It is observed that increasing the number of injured elements in the structures reduces the result precision with algorithms. From results errors, it can be concluded that the PSOPC algorithm has problem in detecting the location of some of the damaged structural elements, so that in the third scenario, the tenth and twentyfourth members which are injured are diagnosed as healthy, 
TABLE 7: The values of objective function of the Bowstring truss for algorithms.

\begin{tabular}{cccccccccccc}
\hline & \multicolumn{8}{c}{ Run number } \\
& 1 & 2 & 3 & 4 & 5 & 6 & 7 & 8 & 9 & 10 & Success \\
\hline $\begin{array}{c}\text { Scenario 1 } \\
\text { CSS }\end{array}$ & $3.2 \times 10^{-05}$ & $4.3 \times 10^{-05}$ & $4.9 \times 10^{-05}$ & $6.9 \times 10^{-05}$ & $7.1 \times 10^{-05}$ & $3.3 \times 10^{-05}$ & $2.6 \times 10^{-05}$ & $7.5 \times 10^{-05}$ & $3.4 \times 10^{-05}$ & $2.6 \times 10^{-05}$ & $100 \%$ \\
PSOPC & $2.6 \times 10^{-07}$ & $4.9 \times 10^{-02}$ & $1.8 \times 10^{-07}$ & $1.3 \times 10^{-01}$ & $1.2 \times 10^{-01}$ & $2.4 \times 10^{-08}$ & $5.0 \times 10^{-08}$ & $1.9 \times 10^{-08}$ & $2.6 \times 10^{-02}$ & $1.7 \times 10^{-02}$ & $60 \%$ \\
Scenario 2 & & & & & & & & & & & \\
CSS & 0.0002 & 0.0003 & 0.0003 & 0.0001 & 0.0039 & 0.0038 & 0.0002 & 0.0003 & 0.0015 & 0.0051 & $60 \%$ \\
PSOPC & 0.0005 & 0.0134 & 0.0672 & 0.0629 & 0.0598 & 0.0050 & 0.0049 & 0.0065 & 0.0123 & 0.0251 & $10 \%$ \\
\hline
\end{tabular}

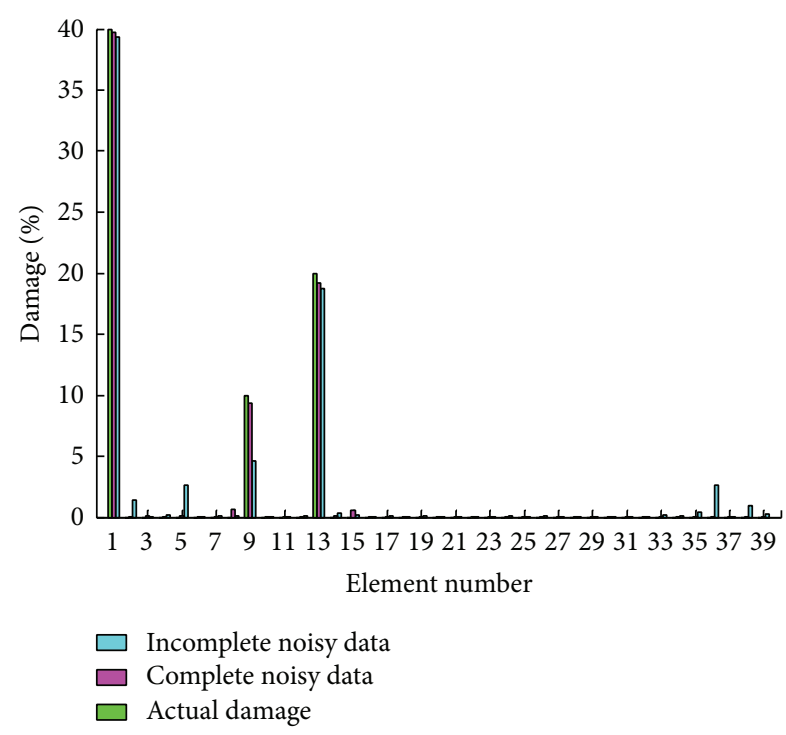

FIGURE 12: Damage distribution of plane frame using the complete and incomplete noisy data in Scenario 1.

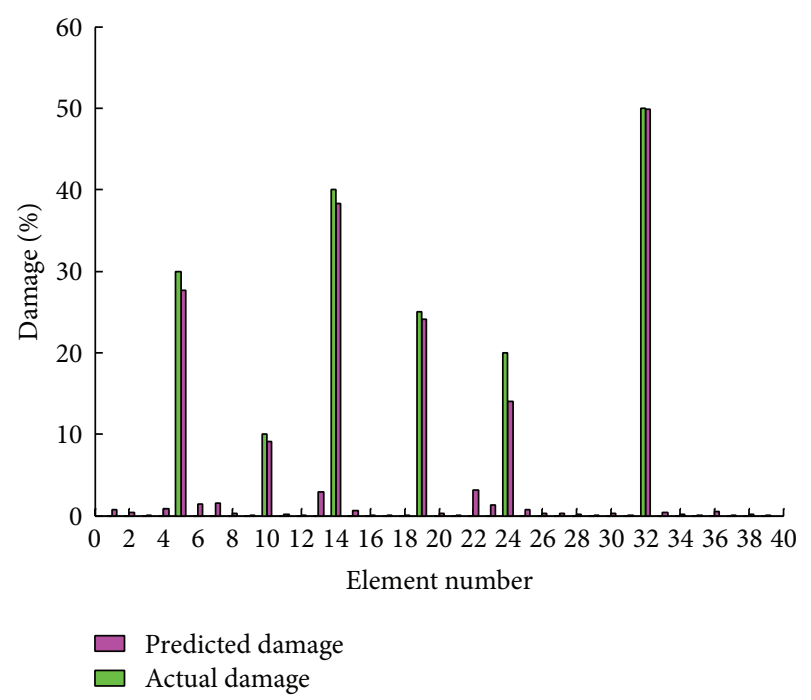

FIGURE 13: Damage distribution of plane frame using the complete noisy data in Scenario 2.
TABLE 8: Simulated damage scenarios in unbraced plane frame.

\begin{tabular}{lcc}
\hline Element number & Scenario 1 & Scenario 2 \\
\hline 1 & $40 \%$ & \\
4 & & $30 \%$ \\
5 & & \\
9 & $10 \%$ & $10 \%$ \\
10 & & \\
13 & $20 \%$ & $40 \%$ \\
14 & & $25 \%$ \\
19 & & $20 \%$ \\
24 & & $50 \%$ \\
32 & & \\
\hline
\end{tabular}

and a considerable amount of damage in the fifteenth and twenty-third elements that have no damage has been gained. However, the CSS algorithm has well identified places of all damaged elements in the structure and has achieved the amount of their damage with high accuracy and low error. From Figures 12 and 13 it can be observed that even in that case a lot of damage to the frame is considered; the effect of noise on the results obtained by the CSS algorithm is low, so that in case of incomplete data, accuracy of results has reduced slightly, and the performance of this algorithm, despite the noise, was considered acceptable.

In all three examples, the convergences diagrams are shown that the process of convergence is gradual. So it causes a more comprehensive search algorithm for finding optimal solutions.

The result increases the success rate of this type of algorithm performance, in comparison with the PSOPC algorithm.

\section{Conclusions}

An approach for detecting damage based on continuum damage model using charged system search algorithm is presented. The algorithm evaluates the location and severity of damage in three structures: a cantilever beam, a Bowstring plane truss, and a three-story three-bay unbraced plane frame by minimizing an objective function by measuring complete and incomplete noisy modal data with different damage scenarios. 
TABLE 9: Results of damage detection of the 39-element frame using CSS and PSOPC algorithms.

\begin{tabular}{|c|c|c|c|c|c|c|}
\hline \multirow{2}{*}{ Element number } & \multicolumn{3}{|c|}{ Scenario 1} & \multicolumn{3}{|c|}{ Scenario 2} \\
\hline & CSS & Actual damage & PSOPC & CSS & Actual damage & PSOPC \\
\hline 1 & 0.399 & 0.400 & 0.393 & 0.005 & 0 & 0.000 \\
\hline 2 & 0.001 & 0 & 0.000 & 0.001 & 0 & 0.000 \\
\hline 3 & 0.001 & 0 & 0.000 & 0.000 & 0 & 0.000 \\
\hline 4 & 0.001 & 0 & 0.027 & 0.037 & 0 & 0.000 \\
\hline 5 & 0.003 & 0 & 0.000 & 0.254 & 0.300 & 0.356 \\
\hline 6 & 0.000 & 0 & 0.000 & 0.016 & 0 & 0.000 \\
\hline 7 & 0.000 & 0 & 0.000 & 0.013 & 0 & 0.000 \\
\hline 8 & 0.005 & 0 & 0.000 & 0.001 & 0 & 0.000 \\
\hline 9 & 0.056 & 0.100 & 0.000 & 0.001 & 0 & 0.000 \\
\hline 10 & 0.002 & 0 & 0.000 & 0.095 & 0.100 & 0.000 \\
\hline 11 & 0.005 & 0 & 0.000 & 0.002 & 0 & 0.000 \\
\hline 12 & 0.008 & 0 & 0.000 & 0.001 & 0 & 0.000 \\
\hline 13 & 0.193 & 0.200 & 0.195 & 0.058 & 0 & 0.000 \\
\hline 14 & 0.001 & 0 & 0.000 & 0.374 & 0.400 & 0.349 \\
\hline 15 & 0.004 & 0 & 0.000 & 0.005 & 0 & 0.115 \\
\hline 16 & 0.000 & 0 & 0.000 & 0.001 & 0 & 0.000 \\
\hline 17 & 0.000 & 0 & 0.000 & 0.001 & 0 & 0.000 \\
\hline 18 & 0.000 & 0 & 0.000 & 0.004 & 0 & 0.000 \\
\hline 19 & 0.000 & 0 & 0.000 & 0.212 & 0.250 & 0.256 \\
\hline 20 & 0.000 & 0 & 0.000 & 0.004 & 0 & 0.000 \\
\hline 21 & 0.000 & 0 & 0.000 & 0.029 & 0 & 0.000 \\
\hline 22 & 0.000 & 0 & 0.002 & 0.015 & 0 & 0.000 \\
\hline 23 & 0.000 & 0 & 0.000 & 0.001 & 0 & 0.092 \\
\hline 24 & 0.000 & 0 & 0.000 & 0.174 & 0.200 & 0.000 \\
\hline 25 & 0.000 & 0 & 0.000 & 0.001 & 0 & 0.000 \\
\hline 26 & 0.000 & 0 & 0.000 & 0.002 & 0 & 0.000 \\
\hline 27 & 0.002 & 0 & 0.000 & 0.005 & 0 & 0.000 \\
\hline 28 & 0.000 & 0 & 0.000 & 0.001 & 0 & 0.040 \\
\hline 29 & 0.000 & 0 & 0.001 & 0.007 & 0 & 0.000 \\
\hline 30 & 0.000 & 0 & 0.000 & 0.000 & 0 & 0.000 \\
\hline 31 & 0.001 & 0 & 0.003 & 0.002 & 0 & 0.000 \\
\hline 32 & 0.000 & 0 & 0.000 & 0.497 & 0.500 & 0.495 \\
\hline 33 & 0.000 & 0 & 0.000 & 0.000 & 0 & 0.000 \\
\hline 34 & 0.006 & 0 & 0.000 & 0.000 & 0 & 0.000 \\
\hline 35 & 0.005 & 0 & 0.025 & 0.001 & 0 & 0.000 \\
\hline 36 & 0.006 & 0 & 0.000 & 0.001 & 0 & 0.000 \\
\hline 37 & 0.002 & 0 & 0.000 & 0.001 & 0 & 0.015 \\
\hline 38 & 0.007 & 0 & 0.000 & 0.001 & 0 & 0.000 \\
\hline 39 & 0.003 & 0 & 0.000 & 0.002 & 0 & 0.000 \\
\hline Error & 0.1162 & & 0.1700 & 0.3600 & & 0.6808 \\
\hline
\end{tabular}

In order to demonstrate the power of this algorithm in the diagnosis of damage, a comparison has been made between the results of this algorithm and the PSOPC algorithm.

By comparing the damage detection results of the two various methods, some interesting points have been concluded. In scenarios where the number of damaged elements is considered low, both algorithms have acceptable accuracy in the results; considering the more damaged members of structures, the PSOPC algorithm has been mistaken to identify the damaged elements of the structure. This problem in larger-scale structures and the increasing number of members has been more visible. CSS algorithm has identified the exact location of damage as well as achieving the amount of damage with acceptable accuracy. It can be concluded that the CSS algorithm has great potential in global and local search of damage. 
TABLE 10: The values of objective function of the 39-element frame for algorithms.

\begin{tabular}{|c|c|c|c|c|c|c|c|c|c|c|c|}
\hline \multicolumn{12}{|c|}{ Run number } \\
\hline & 1 & 2 & 3 & 4 & 5 & 6 & 7 & 8 & 9 & 10 & Success \\
\hline \multicolumn{12}{|l|}{ Scenario 1} \\
\hline CSS & $4.4 \times 10^{-03}$ & $4.6 \times 10^{-03}$ & $8.7 \times 10^{-04}$ & $6.2 \times 10^{-04}$ & $1.1 \times 10^{-03}$ & $6.6 \times 10^{-04}$ & $3.7 \times 10^{-04}$ & $8.0 \times 10^{-04}$ & $2.9 \times 10^{-03}$ & $9.8 \times 10^{-04}$ & $50 \%$ \\
\hline PSOPC & $1.2 \times 10^{-02}$ & $1.3 \times 10^{-02}$ & $4.4 \times 10^{-03}$ & $1.5 \times 10^{-02}$ & $4.3 \times 10^{-02}$ & $1.3 \times 10^{-03}$ & $3.9 \times 10^{-02}$ & $1.4 \times 10^{-02}$ & $3.9 \times 10^{-03}$ & $1.5 \times 10^{-02}$ & $10 \%$ \\
\hline \multicolumn{12}{|l|}{ Scenario 2} \\
\hline CSS & $1.9 \times 10^{-03}$ & $1.3 \times 10^{-03}$ & $1.7 \times 10^{-03}$ & $1.2 \times 10^{-03}$ & $2.3 \times 10^{-03}$ & $2.8 \times 10^{-03}$ & $1.9 \times 10^{-03}$ & $1.1 \times 10^{-03}$ & $2.1 \times 10^{-03}$ & $1.6 \times 10^{-03}$ & $30 \%$ \\
\hline PSOPC & $2.9 \times 10^{-02}$ & $3.9 \times 10^{-02}$ & $1.1 \times 10^{-02}$ & $1.8 \times 10^{-02}$ & $1.1 \times 10^{-02}$ & $5.9 \times 10^{-03}$ & $6.9 \times 10^{-02}$ & $3.6 \times 10^{-02}$ & $5.3 \times 10^{-02}$ & $1.3 \times 10^{-02}$ & $0 \%$ \\
\hline
\end{tabular}

Due to noise, the real value of natural frequencies of structure will change; it can be seen from the diagrams that, in these cases, accuracy reduction of the results of the CSS algorithm is very low. This indicates the high power of this algorithm in damage detection considering noise in structure.

Charged system search by considering small population and low iteration cycle can detect the severity and location of damage with acceptable accuracy which shows high power and speed of convergence of this algorithm. The proposed method by the charged system search algorithm produced better results compared with particle swarm optimization method.

\section{Conflict of Interests}

The authors declare that there is no conflict of interests regarding the publication of this paper.

\section{References}

[1] D. J. Ewins, Modal Testing: Theory and Practice, John Wiley \& Sons, New York, NY, USA, 1984.

[2] S. W. Doebling, C. R. Farrar, and M. B. Prime, "A summary review of vibration-based damage identification methods," Shock and Vibration Digest, vol. 30, no. 2, pp. 91-105, 1998.

[3] N. Hu, X. Wang, H. Fukunaga, Z. H. Yao, H. X. Zhang, and Z. S. $\mathrm{Wu}$, "Damage assessment of structures using modal test data," International Journal of Solids and Structures, vol. 38, no. 18, pp. 3111-3126, 2001.

[4] O. S. Salawu, "Detection of structural damage through changes in frequency: a review," Engineering Structures, vol. 19, no. 9, pp. 718-723, 1997.

[5] N. Bicanic and H.-P. Chen, "Damage identification in framed structures using natural frequencies," International Journal for Numerical Methods in Engineering, vol. 40, no. 23, pp. 44514468, 1997.

[6] A. K. Pandey, M. Biswas, and M. M. Samman, "Damage detection from changes in curvature mode shapes," Journal of Sound and Vibration, vol. 145, no. 2, pp. 321-332, 1991.

[7] J. E. Mottershead and M. I. Friswell, "Model updating in structural dynamics: a survey," Journal of Sound and Vibration, vol. 167, no. 2, pp. 347-375, 1993.

[8] R. Perera and R. Torres, "Structural damage detection via modal data with genetic algorithms," Journal of Structural Engineering, vol. 132, no. 9, pp. 1491-1501, 2006.
[9] S. Fallahian and S. M. Seyedpoor, "A two stage method for structural damage identification using an adaptive neuro-fuzzy inference system and particle Swarm optimization," Asian Journal of Civil Engineering (Building and Housing), vol. 11, pp. 797-810, 2010

[10] B. H. Koh and S. J. Dyke, "Structural health monitoring for flexible bridge structures using correlation and sensitivity of modal data," Computers and Structures, vol. 85, no. 3-4, pp. 117130, 2007.

[11] R.-S. He and S.-F. Hwang, "Damage detection by a hybrid realparameter genetic algorithm under the assistance of grey relation analysis," Engineering Applications of Artificial Intelligence, vol. 20, no. 7, pp. 980-992, 2007.

[12] H. Y. Guo and Z. L. Li, "A two-stage method to identify structural damage sites and extents by using evidence theory and micro-search genetic algorithm," Mechanical Systems and Signal Processing, vol. 23, no. 3, pp. 769-782, 2009.

[13] L. Yu and X. Chen, "Bridge damage identification by combining modal flexibility and PSO methods," in Proceedings of the Prognostics and System Health Management Conference (PHM '10), Macau, China, January 2010.

[14] Z. Tabrizian, E. Afshari, G. Ghodrati Amiri, M. H. A. Beigy, and S. M. Pourhoseini Nejad, "A new damage detection method: Big Bang-Big Crunch (BB-BC) algorithm," Journal of Shock and Vibration, vol. 20, no. 4, pp. 633-648, 2013.

[15] A. Kaveh and S. Talatahari, "A novel heuristic optimization method: charged system search," Acta Mechanica, vol. 213, no. 3-4, pp. 267-289, 2010.

[16] S. M. Pourhoseini Nejad, G. Ghodrati Amiri, A. Asadi, E. Afshari, and Z. Tabrizian, "Damage detection of skeletal structures using particle swarm optimizer with passive congregation (PSOPC) algorithm via incomplete modal data," Journal of Computational Methods in Civil Engineering, vol. 3, no. 1, pp. $1-13,2012$.

[17] S. He, Q. H. Wu, J. Y. Wen, J. R. Saunders, and R. C. Paton, "A particle swarm optimizer with passive congregation," BioSystems, vol. 78, no. 1-3, pp. 135-147, 2004.

[18] X. Wang, N. Hu, H. Fukunaga, and Z. H. Yao, "Structural damage identification using static test data and changes in frequencies," Engineering Structures, vol. 23, no. 6, pp. 610-621, 2001.

[19] A. Messina, E. J. Williams, and T. Contursi, "Structural damage detection by a sensitivity and statistical-based method," Journal of Sound and Vibration, vol. 216, no. 5, pp. 791-808, 1998.

[20] S. W. Doebling, C. R. Farrar, M. B. Prime, and D. W. Shevitz, "Damage identification and health monitoring of structural and 
mechanical systems from changes in their vibration characteristics: a literature review," Research Report LA-13070-MS, ESAEA, Los Alamos National Laboratory, Los Alamos, NM, USA, 1996.

[21] M. Nobahari and S. M. Seyedpoor, "Structural damage detection using an efficient correlation-based index and a modified genetic algorithm," Mathematical and Computer Modelling, vol. 53, no. 9-10, pp. 1798-1809, 2011.

[22] A. Kaveh and S. Talatahari, "Optimal design of skeletal structures via the charged system search algorithm," Structural and Multidisciplinary Optimization, vol. 41, no. 6, pp. 893-911, 2010.

[23] A. Kaveh and S. Talatahari, "Particle swarm optimizer, ant colony strategy and harmony search scheme hybridized for optimization of truss structures," Computers and Structures, vol. 87, no. 5-6, pp. 267-283, 2009.

[24] H. J. Salane and J. W. Baldwin Jr., "Identification of modal properties of bridges," Journal of Structural Engineering, vol. 116, no. 7, pp. 2008-2021, 1990.

[25] O. S. Salawu and C. Williams, "Bridge assessment using forcedvibration testing," Journal of Structural Engineering, vol. 121, no. 2, pp. 161-173, 1995.

[26] J.-M. Ndambi, J. Vantomme, and K. Harri, "Damage assessment in reinforced concrete beams using eigenfrequencies and mode shape derivatives," Engineering Structures, vol. 24, no. 4, pp. 501$515,2002$. 

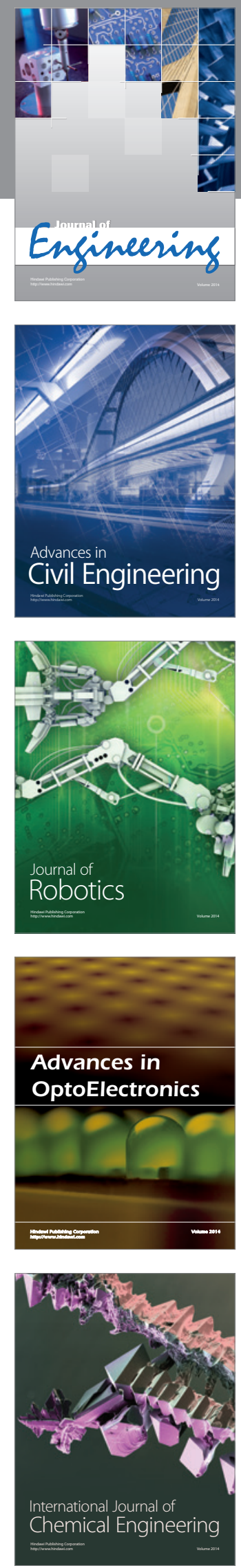

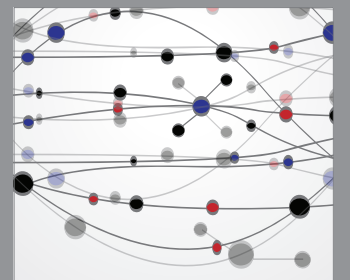

The Scientific World Journal
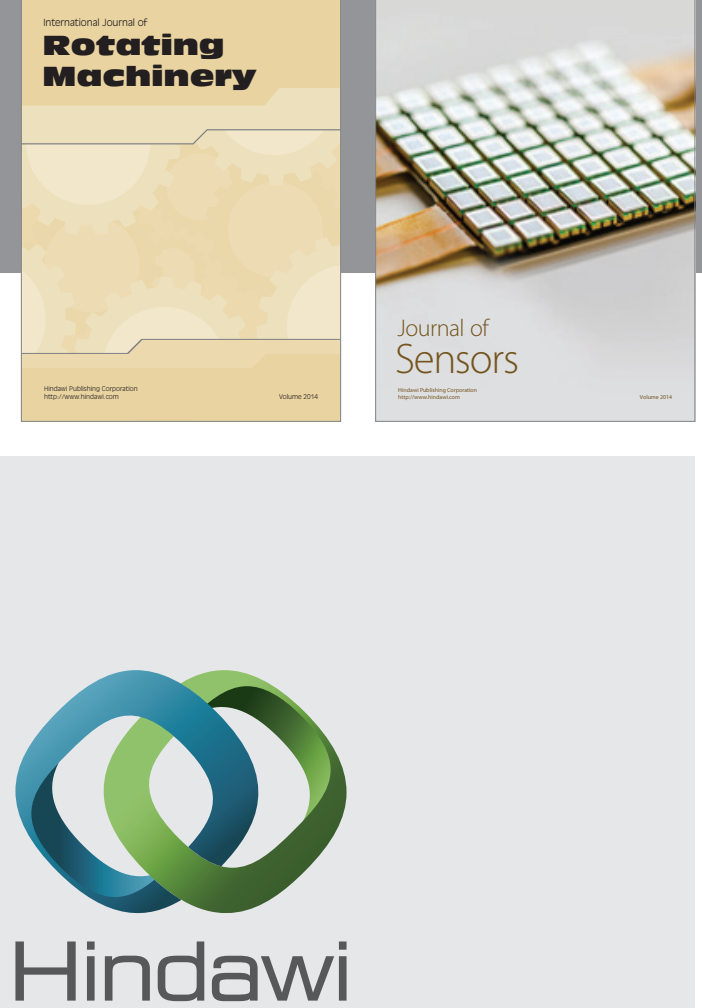

Submit your manuscripts at http://www.hindawi.com
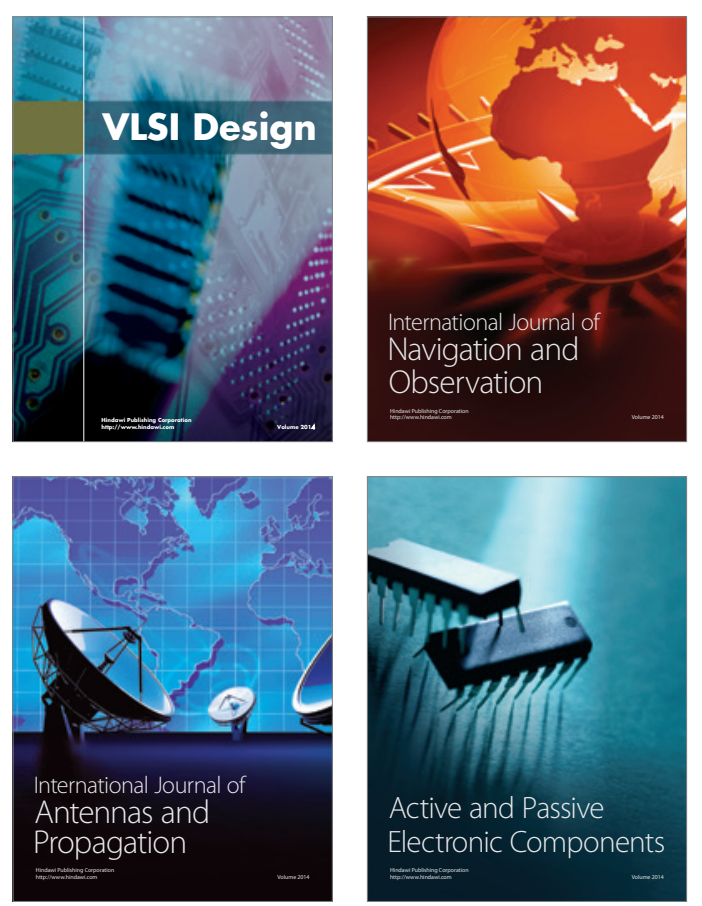
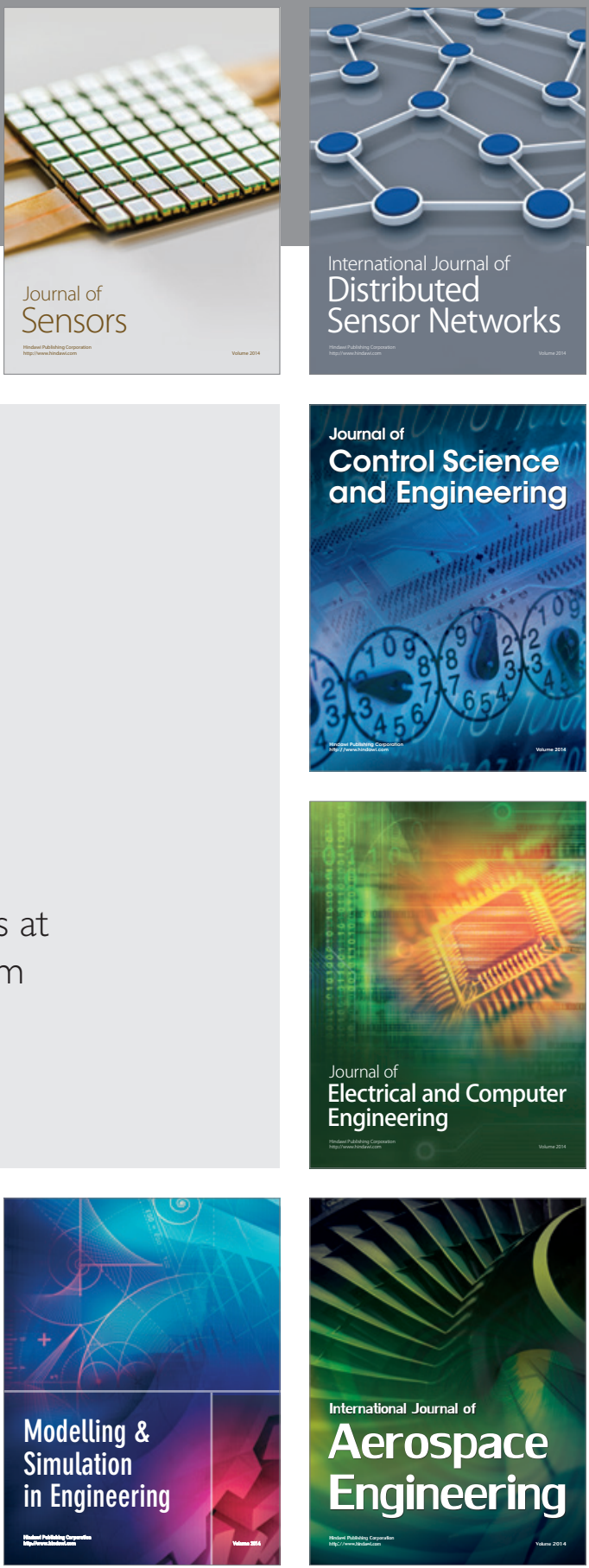

Journal of

Control Science

and Engineering
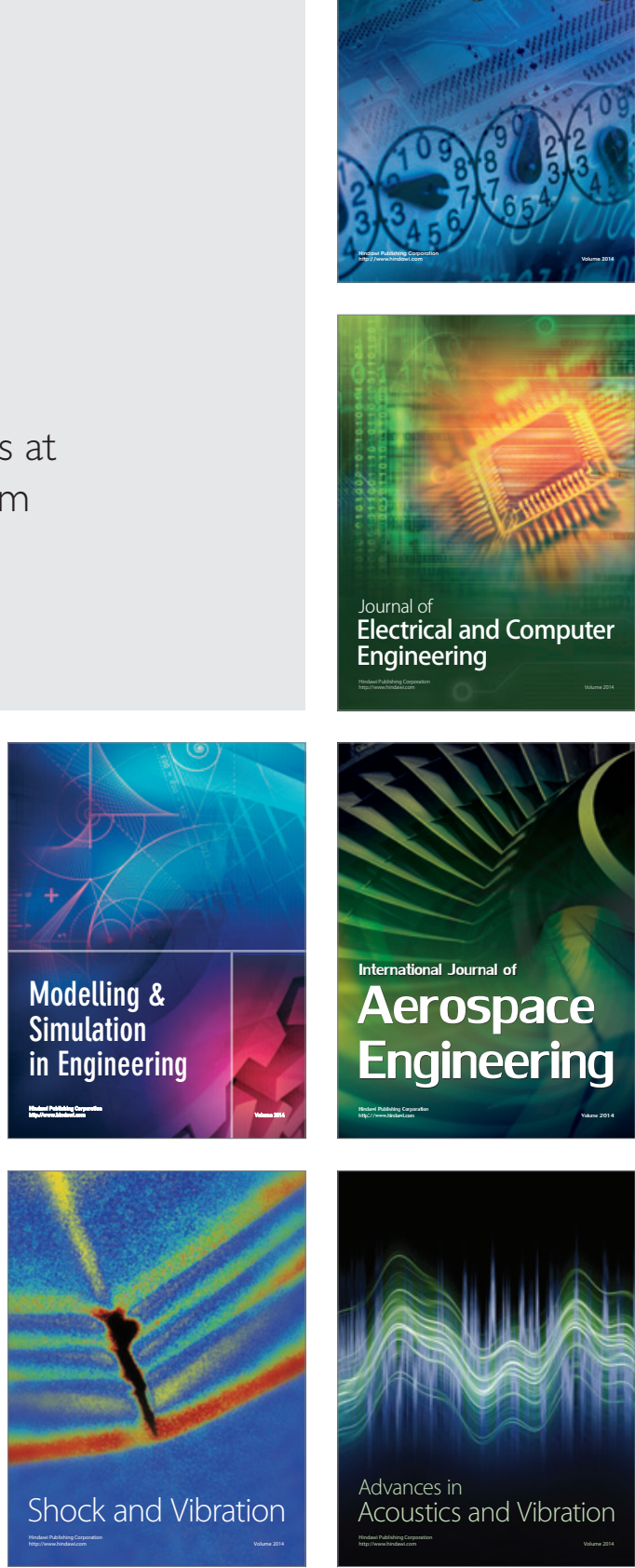